\title{
Think TB in Cervical Lesions Causing Abnormal Vaginal Bleed
}

\section{Guruwadatarhalli $\mathbf{B}^{*}$, Wong $\mathbf{T}$ and Imoh Ita F}

West Middlesex University Hospital, London, UK

\section{Introduction}

A total of 8,751 cases of Tuberculosis (TB) were reported in the UK in 2012, an incidence of 13.9/100,000. 3,426 TB cases were reported in London in 2012, accounting for around $40 \%$ of cases nationally. TB incidence in London is at a worryingly high 42 per 100,000, the highest rate of any western European capital. The majority of cases were among people born outside of the UK and many of these were young adults aged between 25 and 44 . Over 65 year olds account for $14 \%$ of all cases. Screening for latent TB will be key to reducing TB levels in London and there is a need for focused commissioning of services in this area.The cervix is involved in $5-10 \%$ of cases in female genital tract tuberculosis. $\mathrm{TB}$ involvement of the female genital tract in almost all cases is secondary to extragenital tuberculosis. Genital organs most frequently affected include fallopian tubes (95-100\%), endometrium (50-60\%), and ovaries (20-30\%). In $92 \%$ of cases, genital tuberculosis is secondary to a focus in the lungs, lymph nodes, urinary tract, bones, or joints. Given the hormone-dependent nature of female genital tuberculosis, $90 \%$ of cases involve women under 40 years of age [1].

\section{Case Report}

A 72 year old post-menopausal woman was referred to the gynaecology clinic with history of postmenopausal bleeding 4 months after the insertion of ring pessary for uterovaginal prolapse. A suspicious cervical lesion was noted and biopsy revealed inflamed granulation tissue and epitheloid granulomas showing caseation necrosis. Ziehl Nielson stain was negative, but appearance was strongly suggestive of tuberculosis. There was no carcinoma. She was referred to respiratory physicians for further investigations of Chest X Ray and CT chest which showed normal lungs and a $2 \mathrm{~cm}$ mass in left axilla, biopsy of which was negative for TB or cancer. The imaging also helped rule out other differentials of granulomatous lesions like sarcoidosis. She was diagnosed as Cervical TB, counselled and treated with antituberculous medication of Rifmapicin, Ethambutol and Pyridoxine. She had a pelvic ultrasound scan and MRI scan which showed normal abdomen and pelvis. She is being followed up by the colposcopy clinic and the lesion is noted to be reducing in size indicating response to the treatment.

\section{Commentary}

Diagnosis of TB is difficult, as noted in this case and it was arrived as a diagnosis after ruling out cancer and other conditions causing granulomatous changes on histology [2]. In this case it also avoided patient being managed as a case of cancer. Literature review of TB of female genitalia is clear in cases quoted from the developing countries with ZN stains positive for acid fast bacilli, tuberculous bacilli on tissue culture and confirmation of an extra genital source, commonly lungs. However it has been difficult to arrive at the diagnosis in cases reported from the developed countries possibly due to low index of suspicion of TB.

Cases of tuberculous cervicitis are often clinically diagnosed as carcinoma of the cervix since the punctation and mosaic pattern observed on colposcopic examination leads to an erroneous impression of malignancy [1]. The atrophic postmenopausal endometrium is thought to be poorly supportive of tubercle bacilli [2]. Given the recent increase in migration patterns including travel from TB endemic areas, an abnormal-looking cervix should be regarded with a degree of suspicion for TB [3]. The major presenting symptoms are infertility (45-55\%), pelvic pain (50\%), poor general health (25\%), and menstrual disturbances $(20 \%)$ [4]. TB is to be considered in the differentials of reproductive age group, who presents with polymenorrhagia, postcoital bleeding with an unhealthy cervix, discharge per vaginum, lower abdominal pain or growth over the cervix [5]. The presence of epithelioid cells arranged in clusters mixed with Langhans' giant cells in cervicovaginal smears, is highly suggestive of tuberculosis [6].

\section{Conclusion}

With increased migration between developing and developed countries, it is important to think of $\mathrm{TB}$ as a differential diagnosis in women having abnormal vaginal bleeding not responding to traditional management [2]. Appropriate investigation can lead to timely intervention, suitable treatment and contact tracing.

\section{References}

1. Samantaray S, Parida G, Rout N, Giri SK, Kar R (2009) Cytologic detection of tuberculous cervicitis: a report of 7 cases. Acta Cytol 53: 594-596.

2. Rajaram S, Dev G, Panikar N, Singh KC, Goel N (2004) Postmenopausa bleeding: squamous cell carcinoma of cervix with coexisting endometrial tuberculosis. Arch GynecolObstet 269: 221-223.

3. Mukerji S, Moncur L, Sanders B, Currie A, Watson A, et al. (2013) Difficulties in diagnosing tuberculosis of the cervix in a post menopausal woman: Case report and literature review. Australas Med J 6: 367-370.

4. Chowdhury NN (1996) Overview of tuberculosis of the female genital tract. $J$ Indian Med Assoc 94: 345-346, 361

5. Sachan R, Patel ML, Gupta P, Verma AK (2012) Genital tuberculosis with variable presentation: a series of three cases. BMJ Case Rep 2012.

6. Vuong PN, Houissa-Vuong S, Bleuse B, Schoonaërt MF (1989) Pseudotumora tuberculosis of the uterine cervix. Cytologic presentation. Acta Cytol 33: 305308

*Corresponding author: B Guruwadatarhalli, West Middlesex University Hospital London, UK, Tel: +44 208560 21; E-mail: Bramara.Guruwadayarhalli@wmuh.nhs.uk

Received March 11, 2014; Accepted March 22, 2014; Published March 24, 2014

Citation: Guruwadatarhalli B, Wong T, Imoh Ita F (2014) Think TB in Cervical Lesions Causing Abnormal Vaginal Bleed. J Clin Case Rep S1: 004 doi:10.4172/2165-7920.S1-004

Copyright: ( 2014 Guruwadatarhalli B, et al. This is an open-access article distributed under the terms of the Creative Commons Attribution License, which permits unrestricted use, distribution, and reproduction in any medium, provided the original author and source are credited. 